\title{
National Survey Regarding Motivation and Conditions of Physicians Working in a Pediatric Cardiac Intensive Care Unit
}

\author{
Anja Hanser ${ }^{1}$ Michael Hofbeck ${ }^{1}$ Ralf Knies ${ }^{2}$ Matthias Kumpf ${ }^{1}$ Nicole Müller ${ }^{2}$ Ellen Heimberg ${ }^{1}$ \\ ${ }^{1}$ Department for Pediatric Cardiology, Pulmonology and Pediatric \\ Address for correspondence Dr. Anja Hanser, Department of \\ Pediatric Cardiology, Pulmology and Pediatric Care Medicine, \\ Intensive Care Medicine, Universitätsklinikum Tübingen, Tübingen, \\ Baden Württemberg, Germany \\ 2 Department for Pediatric Cardiology, Universitätsklinikum Bonn, \\ University Children's Hospital, University of Tübingen, Hoppe-Seyler- \\ Str. 1, 72076 Tübingen, Germany \\ Bonn, Nordrhein-Westfalen, Germany \\ (e-mail: anja.hanser@med.uni-tuebingen.de).
}

Thorac Cardiovasc Surg 2021;69:e61-e67.

\begin{abstract}
Background The professional demands on the expertise in pediatric intensive care have continuously increased in recent years. Due to a lack of applicants, the staffing of a continuous shift service with qualified medical staff poses major challenges to the hospitals.

Methods A web-based questionnaire with 27 predominantly matrix questions on working conditions and motivation for working in this area was sent to pediatric hospitals throughout Germany.

Results 165 doctors responded to the survey. The average age of the participants was 35.2 years. The average weekend work load reported by $79 \%$ of the respondents was 2 weekends per month, $70 \%$ of the study participants performed five to seven night shifts per month. $92 \%$ of the respondents stated that they basically enjoyed working in the intensive care unit (ICU). When asked to prioritize the working conditions, an appreciative working atmosphere in the team was named as priority 1 by $57 \%$, followed

Keywords

- pediatric cardiac intensive care unit

- pediatric intensive care unit (PICU)

- working conditions

- motivation by good guidance in the independent performance of interventions (25\%) and good working conditions (19\%).

Discussion The survey result shows that neither aspects of work-life balance nor payments are the key issues selecting the interesting, but physically and emotionally demanding job in pediatric ICU.

Conclusion When evaluating vocational training in pediatric intensive care medicine, the immediate working atmosphere in the team with mutual respect and understanding and the guidance in training are more important than the general conditions.
\end{abstract}

\section{Introduction}

Based on fundamental improvements in diagnostics and therapy, the prognosis of critically ill premature and new- born infants has improved greatly in recent decades. However, this has also led to a considerable increase in the complexity of the children treated and thus to increased received

April 20, 2021

accepted after revision

August 30, 2021
DOI https://doi.org/

10.1055/s-0041-1736663.

ISSN $0171-6425$.

\footnotetext{
(C) 2021. The Author(s).

This is an open access article published by Thieme under the terms of the Creative Commons Attribution-NonDerivative-NonCommercial-License, permitting copying and reproduction so long as the original work is given appropriate credit. Contents may not be used for commercial purposes, or adapted, remixed, transformed or built upon. (https://creativecommons.org/ licenses/by-nc-nd/4.0/) Georg Thieme Verlag KG, Rüdigerstraße 14, 70469 Stuttgart, Germany
} 
demands on the expertise and skills of medical staff working in the pediatric intensive care sector. ${ }^{1,2}$ More recent guidelines of the Joint Federal Committee "Gemeinsamer Bundesausschuss" take these additional requirements into account. In German centers which are authorized to perform cardiac surgery in children with congenital heart disease, these guidelines demand among other issues the continuous presence of a fully trained pediatrician who has either started or completed a fellowship in pediatric cardiology. $^{3}$

Perinatal centers, specialized in the treatment of high-risk pregnancies including premature babies below 29 weeks of gestation and birth weight $<1,250 \mathrm{~g}$ (so-called level 1 perinatal centers), must provide a shift service with continuous medical presence and a fully trained neonatologist on call. ${ }^{4}$ The increasing need for highly qualified medical staff to be present in pediatric intensive care units (PICUs) poses a great challenge to hospitals in recruiting staff, as the number of applicants for this psychologically and physically demanding work is very limited. ${ }^{2,5-7}$ To counteract this staff shortage and to make jobs as attractive as possible for applicants, it is necessary to understand the needs and expectations of colleagues who are interested in training in this field. This study deals with the expectations of residents in pediatrics, fellows in training for pediatric cardiology, pediatric intensive care, and neonatology working on intensive care units (ICUs) regarding the framework conditions of their workplace.

\section{Methods}

An online survey was created containing 27 questions (predominantly matrix questions supplemented by nominal, cardinal, and open-ended questions) using web-based software (Survey-Monkey, https://www.surveymonkey.de). The original and translated version of the questionnaire is provided in the - Supplementary Material (online only). The focus of the ICU (pediatric/pediatric cardiology/neonatology) as well as the current level of staff specialization and the working model (possibility of part-time employment, weekend and night workload, shift work model) were queried along with the participant's age and the location of the ICU.

The second part of the survey focused on the prioritization of the attractiveness of working conditions in the ICU. Three subjects had to be rated according to their importance (-Table 1). 1: Good working atmosphere in the team including an appreciative working environment, the opportunity to contribute to therapeutic decisions and mutual respect and understanding in the communication with colleagues and principals. 2: Good guidance in the independent performance of interventions. 3: Good working conditions.

Furthermore, the survey asked for criteria that could improve shift work in an ICU. The following four criteria should be rated according to their importance: (1) better pay, (2) less weekend working time, (3) less night duty, and (4) more days off for compensation following a night duty block (-Table 2). The age ( $<40$ years and $\geq 40$ years) of the participants was taken into account for this question and for preferred night and weekend working hours. This allowed us to record possible differences due to the phase of their personal life.

The survey was distributed to hospitals with PICUs with the help of contacts from the Working Group on Pediatric Cardiac Intensive Care Medicine (AKKI) of the German Society for Pediatric Cardiology (DGPK) and the Pediatric Intensive Care Medicine Section of the German Interdisciplinary Association for Intensive Care and Emergency Medicine (DIVI). It was posted online from August 10, 2018 to August 1, 2019. The prerequisite for participation was a residency in intensive care and intensive care experience of more than 6 months. Formal approval by the local ethics committee was not required (project number: 933/2019BO2) because anonymized data were used in the study.

\section{Results}

A total of 165 participants answered the survey (mean age: 35.2 years [standard deviation: \pm 4.8 ]). Two participants over 50 years were included with the 50 -year-old participants. In total, 138 participants were $<40$ years old and 24 participants $\geq 40$ years old. The responses came from 21 cities. It is not possible to determine the exact rate of responses, as only one contact person at a clinic was contacted and the person forwarded the link to the survey to colleagues in education. The ICUs of the participants in our survey fell into the following categories: (1) PICU, (2) PICU + pediatric cardiointensive care unit, (3) pediatric cardiointensive care unit, (4) PICU + neonatal ICU, (5) neonatal ICU, (6) other ICU.

In summary, $87.2 \%$ of the participants $(n=143 / 164)$ worked in a PICU, of which $75.6 \%$ were associated with heart centers performing surgery of congenital heart disease $(n=124 / 164)$. In addition, $12.8 \%(n=21 / 164)$ of the participants worked in purely neonatal ICUs. About one-third of

Table 1 Assessment of the criteria according to their importance in priority; 1: most important, 2: important, 3: less important

\begin{tabular}{|l|l|l|l|}
\hline & $\mathbf{1}$ & $\mathbf{2}$ & $\mathbf{3}$ \\
\hline $\begin{array}{l}\text { Good working atmosphere in the team } \\
\text { (being able to contribute and have a say) }\end{array}$ & $57.3 \%$ & $29.0 \%$ & $13.8 \%$ \\
$n=79$ & $n=40$ & $n=138$ \\
\hline $\begin{array}{l}\text { Good guidance in the independent performance of interventions } \\
\text { (intubation, central venous line insertion, etc.) }\end{array}$ & $24.8 \%$ & $48.9 \%$ & $26.2 \%$ \\
& $n=35$ & $n=69$ & $n=37$ \\
\hline $\begin{array}{l}\text { Good working conditions } \\
\text { (tolerable shift work, etc.) }\end{array}$ & $19.0 \%$ & $22.5 \%$ & $58.5 \%$ \\
& $n=27$ & $n=32$ & $n=142$ \\
\hline
\end{tabular}

Note: $n$ : number of responses. 
Table 2 Rate shift patterns by importance of priority; 1: most important, 2: very important, 3: less important, 4: not important (subdivided by $<40$ years and $\geq 40$ years)

\begin{tabular}{|c|c|c|c|c|c|c|c|c|c|c|}
\hline & \multicolumn{4}{|c|}{$<40$ years } & & \multicolumn{4}{|c|}{$\geq 40$ years } & \\
\hline & 1 & 2 & 3 & 4 & & 1 & 2 & 3 & 4 & \\
\hline Better payment & $\begin{array}{l}10.1 \% \\
n=12\end{array}$ & $\begin{array}{l}27.7 \% \\
n=33\end{array}$ & $\begin{array}{l}23.5 \% \\
n=28\end{array}$ & $\begin{array}{l}38.7 \% \\
n=46\end{array}$ & $n=119$ & $\begin{array}{l}27.3 \% \\
n=6\end{array}$ & $\begin{array}{l}22.7 \% \\
n=5\end{array}$ & $\begin{array}{l}0.0 \% \\
n=0\end{array}$ & $\begin{array}{l}50.0 \% \\
n=11\end{array}$ & $n=22$ \\
\hline Less weekend working time & $\begin{array}{l}40.0 \% \\
n=48\end{array}$ & $\begin{array}{l}30.8 \% \\
n=37\end{array}$ & $\begin{array}{l}25.0 \% \\
n=30\end{array}$ & $\begin{array}{l}4.17 \% \\
n=5\end{array}$ & $n=120$ & $\begin{array}{l}40.0 \% \\
n=8\end{array}$ & $\begin{array}{l}25.0 \% \\
n=5\end{array}$ & $\begin{array}{l}20.0 \% \\
n=4\end{array}$ & $\begin{array}{l}15.0 \% \\
n=3\end{array}$ & $n=20$ \\
\hline Fewer night shifts & $\begin{array}{l}28.3 \% \\
n=34\end{array}$ & $\begin{array}{l}16.7 \% \\
n=20\end{array}$ & $\begin{array}{l}27.5 \% \\
n=33\end{array}$ & $\begin{array}{l}27.5 \% \\
n=33\end{array}$ & $n=120$ & $\begin{array}{l}23.8 \% \\
n=5\end{array}$ & $\begin{array}{l}33.3 \% \\
n=7\end{array}$ & $\begin{array}{l}28.6 \% \\
n=6\end{array}$ & $\begin{array}{l}14.3 \% \\
n=3\end{array}$ & $n=21$ \\
\hline $\begin{array}{l}\text { More days off for } \\
\text { compensation following } \\
\text { night shifts }\end{array}$ & $\begin{array}{l}21.7 \% \\
n=26\end{array}$ & $\begin{array}{l}25.0 \% \\
n=30\end{array}$ & $\begin{array}{l}24.2 \% \\
n=29\end{array}$ & $\begin{array}{l}29.2 \% \\
n=35\end{array}$ & $n=120$ & $\begin{array}{l}13.6 \% \\
n=3\end{array}$ & $\begin{array}{l}18.2 \% \\
n=4\end{array}$ & $\begin{array}{l}50.0 \% \\
n=11\end{array}$ & $\begin{array}{l}18.2 \% \\
n=4\end{array}$ & $n=22$ \\
\hline
\end{tabular}

Note: $n$ : number of responses.

the participants (32.7\%, $n=54 / 165)$ were residents in specialist training in pediatrics and adolescent medicine. The majority of participants were fully trained pediatricians in subspecialty training for pediatric cardiology $(32.7 \%, n=54)$, pediatric intensive care $(14.6 \%, n=24)$ or neonatology $(6.1 \%$, $n=10)$, and fully trained pediatric cardiologists $(5.5 \%, n=9)$. A further $7.3 \%(n=12)$ were pediatricians without a postgraduate training position or fully trained anesthetists in subspecialty training for intensive care medicine $1.2 \%$ $(n=2)$.

\section{Actual State/General Conditions}

One-third of the participants $(32.9 \%, n=54 / 164)$ stated that a fully trained pediatrician (pediatric specialist frequently performing subspecialist training/fellowship) was present permanently on site in the ICU, while $14.0 \%(n=23)$ answered that their institution at least tried to ensure continuous presence of fully trained pediatricians among the assistant doctors. The other participants declared that pediatric specialists were not always present on shift duty. A total of $55.6 \%(n=79 / 142)$ of the respondents stated that experienced doctors (including fully trained pediatricians or colleagues in their last year of pediatric training) were predominantly assigned to late and night duty. The possibility of part-time employment was affirmed by the majority of respondents (83.3\%, $n=120 / 144$ ); among those aged $\geq 40$, this was $95 \%$. Weekend work time included an average of 2 weekends/month for $78.5 \%(n=113)$ of the participants, 3 weekends per month for $11.1 \%(n=16)$, and 1 weekend per month for $6.3 \%(n=9)$. During the week, $62.1 \%(n=90 / 145)$ of the respondents worked in a three-shift system and on weekends in a two-shift system. A total of $9.0 \%(n=13)$ of the respondents worked in a continuous two-shift system and $27.6 \%(n=40)$ worked in a continuous three-shift system. Twelve-hour shifts were perceived as too stressful by $52.5 \%$ $(n=75 / 143)$ of respondents.

The frequency peak of the average number of night duties was 7 per month $(34.0 \%, n=48 / 141)$, with a variation between 4 and 10 night duties per month ( - Fig. 1a; number of nights per night duty block, - Fig. 1b). Following a night duty block, half of the participants (50.4\%) received 1 to 2 compensation days, whereby the day immediately following the night duty was not included (-Fig. 1c).

\section{Motivation/Perspective}

A total of $92.3 \%(n=132 / 143)$ of the participants stated that they enjoyed working in a PICU in principle. Moreover, 65.0\% $(n=93)$ could imagine undergoing further subspecialty training in pediatric intensive care medicine, while $12.6 \%$ $(n=18)$ were already undergoing this training.

When answering the question of what priorities they would set when evaluating the working conditions, the respondents considered an appreciative working environment and a good working atmosphere in the team to be the most important issue. This was selected as priority 1 by $57.3 \%$ $(n=79)$ of respondents. Good guidance during interventions followed at a considerable distance in priority $1(24.8 \%$, $n=35$ ), while good working conditions came third with $19.0 \%(n=27)$. Priority 2 was dominated by good guidance in the performance of invasive procedures, such as intubations or placement of central venous catheters, with $48.9 \%$ $(n=69)$ of respondents. In priority 3, a majority of $58.5 \%$ $(n=83)$ of the respondents mentioned good working conditions, such as tolerable shift work ( - Table 1 ).

When answering the question which criterion should be prioritized to make shift work in an ICU more attractive, priority 1 was most often given to less weekend working time, regardless of the age of the respondents ( - Table 2 ). Among $<40$-year-olds, priority 1 was followed in second place by fewer night duties, followed by more days off following a night duty block. Better pay was only mentioned in the fourth place under priority 1 . Also under priority 2 , the largest group of respondents opted for the desire for fewer weekend working hours; under priority 3 the largest number of respondents chose fewer night services; while under priority 4 the desire for better pay dominated (-Table 2 ). Among those aged $\geq 40$ years, the wish for better pay followed by fewer night services and more days off following night services was mentioned in the second place under priority 1 . In this age group, priority 2 was dominated by the 

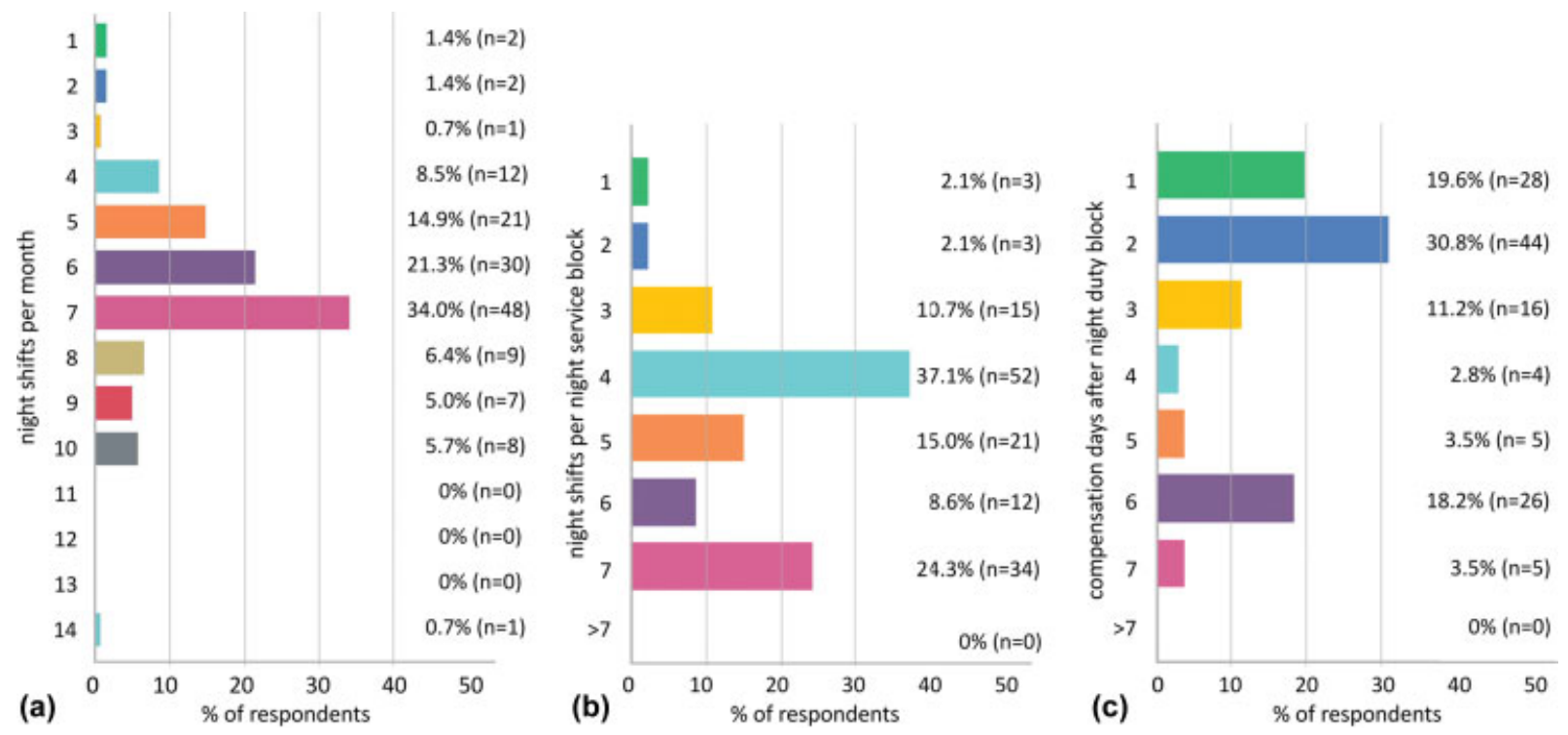

Fig. 1 (a) Average number of night shifts worked per month. $n=$ number of responses. (b) Number of night duties performed on average per night duty block. $n$ : number of responses. (c) Average number of compensation days after a night duty block. The day directly following the night shift was not counted as a compensation day. $n$ : number of responses, additionally $n=15$ free text answers.

wish for less night work, and priority 3 by the wish for more days off after night work. In this age group, too, a clear peak for better pay only emerged under priority 4 (-Table 2 ).

Among the $<40$-year-olds, $61.2 \%$ of the respondents said that in a case of a workload exceeding 3 weekends per month, the job became less attractive to them. In contrast, $61.9 \%$ of those aged $\geq 40$ answered that from 2 weekends per month onwards, the job became less attractive to them (-Fig. 2a). Regarding the number of night services in a row that are still considered tolerable, $77.5 \%$ of the respondents $<40$ years named several three to five services. Among participants $\geq 40$ years, $71.4 \%$ of participants named a range of two to four services (-Fig. 2b). It was remarkable in this group that $23.8 \%$ of the participants also rated a sequence of seven night services as still tolerable (-Fig. 2b). Among the study participants $<40$ years of age, the majority $(75.6 \%)$ named 2 to 3 days off work as adequate recovery time following a night duty block of 4 nights, with a frequency peak at 3 days ( - Fig. 2c). In the group of those aged $\geq 40$ years, the respondents reported 2 to 4 days off work with approximately the same distribution (-Fig. $\mathbf{2 c}$ ). The day on which the night service ends was not counted as a compensation day. There was no relevant difference in the responses of participants working in ICUs with less than 11 full-time positions as compared with participants working in larger units employing more than 11 full-time physicians.

\section{Discussion}

The growing complexity of pediatric intensive care medicine requires a high level of competence from residents in this field, combined with a heavy workload due to shift and weekend duty. Increased quality requirements ${ }^{3,4}$ and declining numbers of applicants in line with general trends $s^{6,7}$ pose great challenges to the clinic's management team. What is remarkable about our survey is the fact that $92.3 \%$ of the respondents stated that they enjoyed working in an ICU in principle and $65.0 \%$ of the respondents could in principle imagine completing the training in special intensive care medicine. How can clinics attract these potential applicants to work in the PICU?

A total of $87.2 \%$ of respondents reported working in a PICU, of which $75.6 \%$ had a pediatric cardiology focus. The latter ICUs at pediatric cardiac surgery centers contain a critical patient population requiring a high level of attention with rapid action, be it in the context of cardiac arrhythmias, bleeding, or coagulation disorders after complex interventions.

Working in a PICU is emotionally and physically demanding. ${ }^{8-13}$ Shift work means that social contacts and family life, which mainly take place in the evenings and at weekends, are considerably impaired by the professional activity. ${ }^{14}$ Especially for the $\geq 40$-year-olds, the attractiveness of the job decreases significantly in case of a workload exceeding weekends two per month (-Fig. 2a). Night shifts are also physically demanding due to the changing day-night rhythm. ${ }^{15}$ The vast majority of all respondents stated that they worked an average of seven night shifts per month. The majority of respondents in the $<40$-year-old group found up to four night shifts at a stretch well tolerable, and in the $\geq 40$ year-old group up to three night services at a stretch. In our survey, most respondents received two free compensation days following a night duty block. However, 3 compensation days following a night duty block of 4 nights to re-synchronize the day-night rhythm were considered adequate in the majority of both age groups. This illustrates the eminent importance of creating duty models that, while optimizing shift rotation patterns, shift duration, and duration of time off between shifts, allow for adequate regeneration of staff and thus ensure their efficiency. ${ }^{16}$

In our survey, an excellent working climate in the unit was clearly more important than the general work 

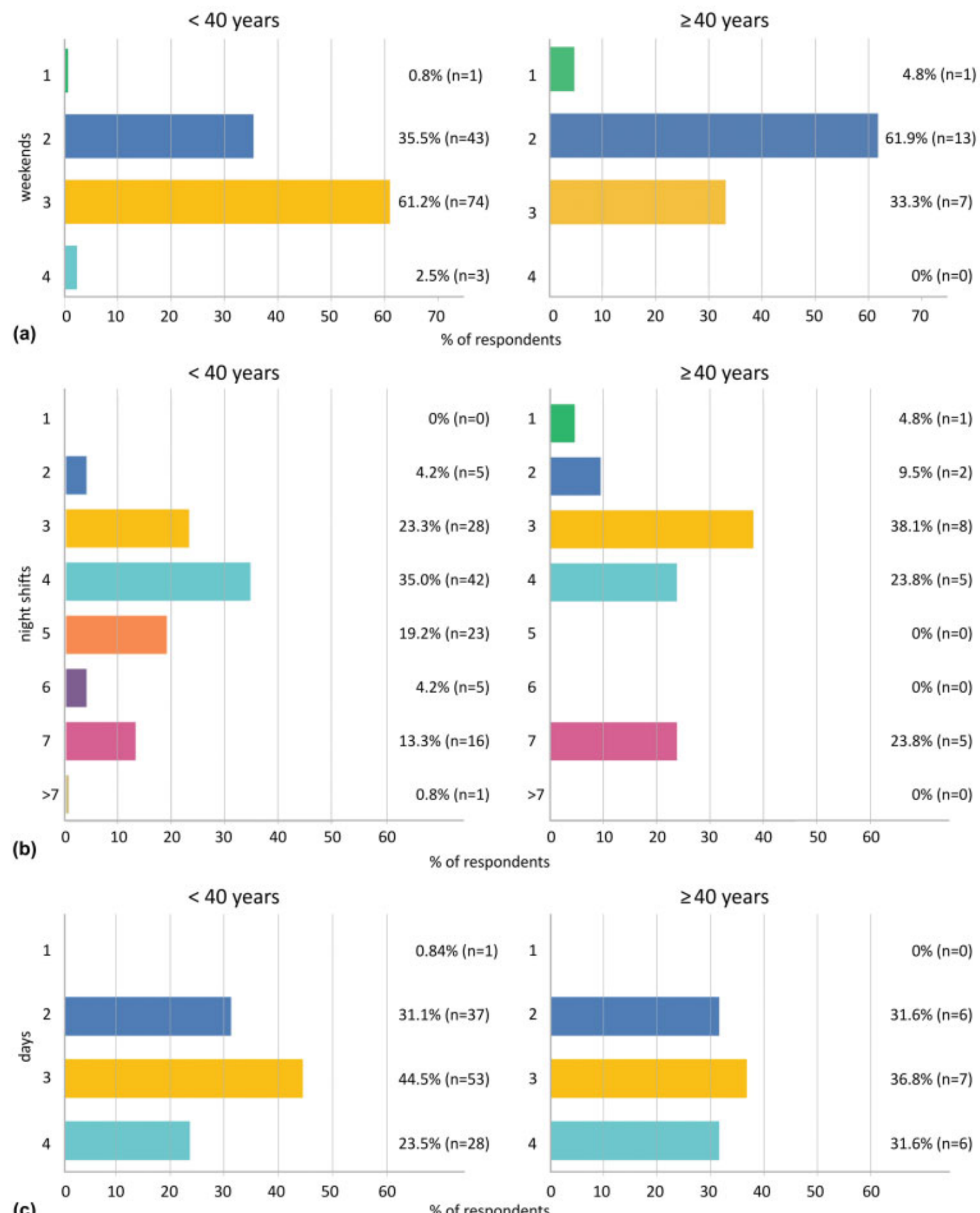

(c)

Fig. 2 (a) Number of weekends per month after the job becomes less attractive (subdivided into $<40$ years and $\geq 40$ years). $n$ : number of responses. (b) Number of night shifts per night service block that are perceived as well tolerated (subdivided into $<40$ years and $\geq 40$ years). $n$ : number of responses. (c) Number of compensation days to a service of 4 nights perceived as appropriate (subdivided into $<40$ years and $\geq 40$ years). $n$ : number of responses.

conditions. The mutual respect, the support in the team as well as the possibility being involved in the decision making about patient care were mentioned by the respondents as the most important factors for choosing to work in a PICU.
These criteria are followed by good instructions on how to carry out invasive procedures independently, while the framework conditions were rated as less important by the majority. 
Our survey clearly confirms the statements made in earlier work on the topic of "Generations in the Hospital,"17,18 that the inner-clinical working environment and the appreciative guidance for independent activity are the main criteria for taking on a physically and psychologically stressful activity. ${ }^{19}$ According to our survey, the willingness to work weekends decreases with increasing age. This speaks against a "generation conflict" 20,21 with increased attention to the so-called "work-life balance" by the younger generation, but rather suggests that an orderly family life/social life with many weekend shifts becomes less feasible with increasing age. ${ }^{22}$ Social compensation in particular helps staff to deal with stressful borderline situations, to cope with a heavy workload, ${ }^{23}$ and it can improve patient care. ${ }^{23-25}$

Also, with increasing age, respondents indicated that they consider fewer night shifts en bloc to be tolerable. The possibility of part-time employment can reduce the workload/number of night shifts. Our survey shows that hospitals are already responding in this regard, as parttime employment in the ICU was already possible in the vast majority of institutions. While part-time employment appears helpful to increase motivation and reduce the workload, there is probably a lower limit of employment required to maintain the necessary skills for treatment of these complex patients. In addition, increasing employment of part-time physicians will make it challenging to ascertain continuity in patient care. In the future these questions will have major impact in the successful organization of PICUs. The survey result shows that neither the so-called "work-life balance," in the sense of an increased weighting of time off work, nor pay is the main motivator for choosing an interesting, but also exhausting and emotionally stressful job. Especially for the strenuous work in a PICU, an appreciative working environment in the team is important. ${ }^{26}$ Activities with family and friends mainly take place at weekends, matching the survey result "more than two weekends per month lowers the attractiveness of the workplace."

This issue was taken into account in the recent collective agreement negotiated with the German Physicians' representation “Marburger Bund" on March 7, 2020 for university hospitals and on May 22, 2019 for municipal hospitals, which limits the number of average weekend shifts to two per month. ${ }^{27}$

Another approach to improve the framework conditions could be to limit night shift blocks and to grant adequate free compensation days. ${ }^{11,28}$

\section{Limitations}

Limitations of the present survey include the limited number of participants. The response rate could not be precisely determined, as individuals were not specifically contacted, but the link to the survey was passed on within the clinics. The responses came from 21 German cities. The DIVI reported in 2015 a total number of 77 PICUs in Germany. Based on data of the AKKI, 20 of these units are either exclusively or partially dedicated to pediatric cardiac intensive care following surgery of congenital heart disease. Since only a relatively small proportion of the responses in our survey came from neonatal ICUs while $75.6 \%$ of our respondents reported to work in PCICUs, the results to a large extent reflect the motivations and conditions of physicians working in the latter units. The data of the survey did not allow the night shifts and weekend shifts to be calculated and evaluated as a percentage of possible part-time employment.

\section{Conclusions}

The working atmosphere, the mutual appreciation in the team, and the guidance in the independent performance of invasive procedures form the greatest incentive to work in a PICU on shift duty. The framework conditions for social contacts and family, and here especially the number of free weekends, are particularly important and serve to balance the often stressful activities. Positive impulses can be expected here from the implementation of the current, new collective agreement for university hospitals as of October 1, 2020. ${ }^{27}$

According to our survey, financial compensation under present conditions in Germany appears to be of secondary importance when it comes to deciding on a postgraduate training position in pediatric intensive care medicine. Thus, the conclusion of the survey can be summarized as follows: the working environment in a team where people feel respected and supported is more important than work-life balance.

\section{Conflict of Interest}

None.

\section{Funding/Acknowledgments}

We thank the Working Group for Pediatric Cardiac Intensive Care Medicine (AKKI) of the German Society for Pediatric Cardiology and Congenital Heart Disease (DGPK) and the Section for Pediatric Intensive Care Medicine of the German Interdisciplinary Association for Intensive Care and Emergency Medicine (DIVI) for supporting us with their contacts with the clinics.

We thank PAEDSIM (Teamtraining für Kindernotfälle e.V.) for their support in conducting the survey.

We thank the Stiftung zur Förderung der Erforschung der Zivilisationserkrankungen for their financial support.

\section{References}

1 Warncke G, Hoffmann F, Sasse M, et al. A multinational survey on the infrastructural quality of paediatric intensive care units. Ann Intensive Care 2018;8(01):105

2 Michel J, Hofbeck M, Gerster L, Neunhoeffer F. Medical staffing in neonatal and pediatric intensive care units - an European survey [in German]. Klin Padiatr 2019;231(05):255-261

3 GBA. Gemeinsamer Bundesausschuss. Richtlinie über Massnahmen zur Qualitätssicherung der herzchirurgischen Versorgung bei Kindern und Jugendlichen gemäß §136 Absatz 1 Satz 1 Nummer 2 SGB V. Fassung vom 18.02.2010, zuletzt geändert 14.05.2020, Inkraftgetreten: 14. 05 2020., DOI

4 GBA. Gemeinsamer Bundesausschuss. Richtlinie über Maßnahmen zur Qualitätssicherung der Versorgung von Früh- und 
Reifgeborenen gemäß §136 Absatz 1 Satz 2 Nummer 13 SGB V. Fassung vom 20.09.2005, zuletzt geändert 14.05.2020, Inkraftgetreten: 14. 05 2020., DOI

5 Blum K, Löffert L, Offermanns M, Steffen P. Krankenhaus Barometer Umfrage 2019. Available athttps://www.dkgev.de/fileadmin/ default/Mediapool/3_Service/3.4._Publikationen/3.4.5._Krankenhaus_Barometer/Krankenhaus_Barometer_2019.pdf

6 Martin W. Nachfrage nach Fachärzten sprunghaft gestiegen. Dtsch Arztebl 2016;113:2-4

7 Martin W. Wettbewerb um qualifizierte Fachärzte verschärft sich. Dtsch Arztebl 2018;115:2-4

8 Fields AI, Cuerdon TT, Brasseux CO, et al. Physician burnout in pediatric critical care medicine. Crit Care Med 1995;23(08): $1425-1429$

9 Rodríguez-Rey R, Palacios A, Alonso-Tapia J, et al. Are pediatric critical personnel satisfied with their lives? Prediction of satisfaction with life from burnout, posttraumatic stress, and posttraumatic growth, and comparison with noncritical pediatric staff. Pediatr Crit Care Med 2019;20(03):e160-e169

10 de Cordova PB, Phibbs CS, Bartel AP, Stone PW. Twenty-four/seven: a mixed-method systematic review of the off-shift literature. J Adv Nurs 2012;68(07):1454-1468

11 Korzilius H. Ärzte fühlen sich überlastet. Dtsch Arztebl 2020; 117:168-169

12 Vincent-Höper S, Stein M, Pohling U, Felsberg R, Bobbert P, Nienhaus A. Gemeinsam gegen die Ökonomie. Dtsch Arztebl 2020;117:1043-1047

13 Weyersberg A, Roth B, Köstler U, Woopen C. Gefangene zwischen Ethik und Ökonomie. Dtsch Arztebl 2019;116:1586-1591

14 Matthews RA, Swody CA, Barnes-Farrell JL. Work hours and workfamily conflict: the double-edged sword of involvement in work and family. Stress Health 2012;28(03):234-247

15 Caruso CC, Bushnell T, Eggerth D, et al. Long working hours, safety, and health: toward a National Research Agenda. Am J Ind Med 2006;49(11):930-942
16 Ganesan S, Magee M, Stone JE, et al. The impact of shift work on sleep, alertness and performance in healthcare workers. Sci Rep 2019;9(01):4635

17 Schmitt-Sausen N. Chefärzte müssen umdenken. Dtsch Arztebl 2020;117:56-58

18 Schmedt M. Generationen im Krankenhaus: Der Wandel ist nicht zu stoppen. Dtsch Arztebl 2020;117:274-276

19 Paulmann V, Kuhlmann E. Weckruf für die Fachkräftesicherung. Dtsch Arztebl 2019;116:729-731

20 Spielberg P. Das Problem ist nicht unlösbar. Dtsch Arztebl 2019; 116:986-987

21 Schmidt C, Möller J, Windeck P. Vier Generationen unter einem Dach. Dtsch Arztebl 2013;110:928-933

22 Gibis B, Heinz A, Jacob R, Müller C-H. The career expectations of medical students: findings of a nationwide survey in Germany. Dtsch Arztebl Int 2012;109(18):327-332

23 Horst JP, Michel M, Kubicki R, Lang N, Zschirnt M, Moosmann J. National survey on training in pediatric cardiology by the "Junges Forum" of the DGPK. Thorac Cardiovasc Surg 2020;68(S 03):e1-e8

24 Dasgupta S, Dave I, McCracken CE, Mohl L, Sachdeva R, Border W. Burnout and work-life balance among pediatric cardiologists: a single center experience. Congenit Heart Dis 2019;14(03):350-355

25 Saini A. Work-life balance: keep the cycle moving - find a purpose, set priorities, and manage time well then reassess and reset. Front Pediatr 2016;3:118

26 Rodríguez-Rey R, Palacios A, Alonso-Tapia J, et al. Burnout and posttraumatic stress in paediatric critical care personnel: prediction from resilience and coping styles. Aust Crit Care 2019;32(01):46-53

27 Tarifvertrag für Ärztinnen und Ärzte an Uiversitätskliniken (TVÄrzte) available at http://www.marburger-bund.de/sites/default/ files/tarifvertraege/2020-06/20-06-02\%20TV-\%C3\%84rzte\%20i.d. F.\%207.\%C3\%84nderungsTV.pdf

28 Driscoll TR, Grunstein RR, Rogers NL. A systematic review of the neurobehavioural and physiological effects of shiftwork systems. Sleep Med Rev 2007;11(03):179-194 